\title{
DO MULTIPLE CHRONIC CONDITIONS INFLUENCE PERSONAL VIEWS ON THE AGEING PROCESS? A QUALITATIVE ANALYSIS
}

\author{
R.E. Pel-Littel 1,2, M. van Rijn ${ }^{1,3}$, P.W. Vermunt ${ }^{2}$, J.C.M. van Weert ${ }^{4}$, M.M.Minkman ${ }^{2,5}$, G. ter Riet' ${ }^{6}$, \\ W.J. Scholte op Reimer ${ }^{3,7}$, B.M. Buurman ${ }^{1,3}$
}

\begin{abstract}
Objectives: For older persons with two or more chronic diseases (multiple chronic conditions) insight into what they perceive as important in their lives is essential when discussing preferences in the shared decision making process. The aims of this study were to 1) investigate the personal views on the ageing process communicated by older persons and 2) compare the personal views of older persons with and without multiple chronic conditions. Design: Using structured interviews participants were asked five questions about what they perceived as important in terms of ageing, worries, their future, healthy ageing and quality of life. Two independent researchers coded the data and performed content analyses. A stratified content analysis was performed to explore whether persons with and without multiple chronic conditions expressed different personal views with regard to the ageing process. Participants $\mathcal{E}$ setting: 547 community dwelling older persons aged 70 years and above. Results: The mean (SD) age was 78.9 (5.9) years, and 60.3\% were female. Multiple chronic conditions were present in $72 \%$ of the study sample. There were no significant differences in demographic characteristics between persons with and without multiple chronic conditions . However persons with multiple chronic conditions more often had polypharmacy (43\% vs $24 \%$; p $<0.001$ ), more difficulties with (instrumental) activities of daily living (mean number of impairments 2.4 vs $0.8 ; \mathrm{p}<0.001$ ) and reported more falls (35\% vs $23 \%$ $\mathrm{p}=0.01$ ) than those without multiple chronic conditions. The qualitative analysis identified the following main themes: ageing was associated with acceptance of ageing, (further) deterioration and worries about limitations and family. A healthy lifestyle, keeping busy, maintaining social contacts and a positive attitude were considered prerequisites to healthy ageing. In 24 out of 28 sub-themes no significant differences were found between participants with and without multiple chronic conditions (MCC). Persons with multiple chronic conditions more often expressed that ageing for them meant having to cope with deterioration and limitations, they had more worries and feared more deteriorations compared to those without multiple chronic conditions. Also persons with multiple chronic conditions less often considered a positive attitude to life a prerequisite to healthy ageing. Conclusions: Acceptance of ageing, (further) deterioration and worries about limitations and family were important themes on the ageing process communicated by older persons. Overall, we found no major differences between persons with and without multiple chronic conditions. The results of this study may help raising awareness amongst health care professionals that eliciting and understanding an older persons' views on the ageing process is an important first step in making health decisions that support older persons' personal goals and expectations.
\end{abstract}

Key words: Older persons, preferences, multiple chronic conditions, shared decision making.

\section{Introduction}

Older persons with multiple chronic conditions (MCC) face many health-related decisions, including those

1. Department of Internal Medicine, Section of Geriatric Medicine, Academic Medical Centre, University of Amsterdam, Amsterdam, The Netherlands; 2. Vilans Centre of expertise for long-term care, Utrecht, the Netherlands; 3. ACHIEVE Centre of Expertise, Faculty of Health, Amsterdam University of Applied Sciences, Amsterdam, The Netherlands; 4. Amsterdam School of Communication Research/ASCoR, University of Amsterdam, Amsterdam, The Netherlands; 5. University of Tilburg/TIAS school for Business and Society, Tilburg, The Netherlands; 6. Department of General Practice, Academic Medical Centre, University of Amsterdam, Amsterdam, The Netherlands; 7. Department of Cardiology, Academic Medical Centre, University of Amsterdam, Amsterdam, The Netherlands

Corresponding Author: Ruth Pel-Littel, RN MSN, Department of Internal Medicine, section of Geriatric Medicine, Academic Medical Centre, University of Amsterdam, PO Box 22660, 1100 DD Amsterdam, The Netherlands, r.pel@vilans.nl

Received May 2, 2017

Accepted for publication July 21, 2017 related to diagnostic procedures, medication use and invasive treatments $(1,2)$. MCC is defined as having two or more chronic conditions (1). For professionals caring for older persons with MCC is challenging due to the limitations of single-disease-focused guidelines, which do not take into account the complexity of MCC and are sometimes contradictory (3). Moreover, having MCC often leads to problems in the functional, social or psychological domains $(2,4)$. The presence of MCC in older persons influences their goals and expectations of medical treatment; for older persons with MCC maintaining independence and quality of life becomes more important than survival (5). The American Geriatrics Society stated that especially for older persons with MCC it is necessary to elicit their personal values and views before starting medical treatment (2). These personal values and views might contribute to the 
agreement between diagnostic procedures and treatment and the outcomes that are important to an older person

The dynamic model for shared decision-making in frail older patients(13) presents this clarification of personal values and views as an important first step preceding the talk in which options are presented and preferences must be articulated about the various options. The best option always depends on the person's individual preferences regarding the preferred outcome, such as quality of life or survival $(10,14)$. However, as stated in the literature identifying a person's values, is not yet a regular component of health care conversations $(8,10,15)$. Health care professionals often lack routine practices in eliciting older persons' preferences, and older persons often lack the confidence to express them $(10,15-17)$.

This study wants to contribute in exploring the personal views of older persons with and without MCC in order to raise awareness among health care professionals regarding the topics that are important to older persons. This supports the first step in making shared decisions, namely exploring an older persons personal goals and expectations. The aim of this study was to 1) investigate which personal views on the ageing process older persons hold and 2) compare the views of older persons with and without MCC.

\section{Methods}

\section{Design and setting}

Baseline data from a cluster randomized clinical trial (C-RCT) and a prospective cohort study were combined for this study. The aim of the C-RCT was to investigate whether functional decline in community-dwelling older persons can be delayed or prevented by a comprehensive geriatric assessment, multifactorial interventions and nurse-led care coordination $(18,19)$. The overall effects of this C-RCT yielded neutral findings (18). For the present study, we included community-dwelling persons aged $>70$ years from two GPs in IJmuiden, the Netherlands, participating in the intervention arm of the C-RCT. Additionally, we performed a prospective cohort study in the region of Amsterdam among eight GPs in the Netherlands. Both studies were conducted between December 2010 and 2014. Details on the C-RCT have been published elsewhere $(18,19)$.

\section{Participants and recruitment}

All community dwelling persons who were 70 years and older and registered with one of the participating GPs were selected from the electronic medical records by their GP. Persons were excluded if they were terminally ill, suffered from dementia, did not understand Dutch, planned to move or spend a long time abroad or lived in a nursing home. Eligible persons received a letter with information on the study from their GP, together with a written informed consent form, a self-reporting questionnaire and a stamped envelope (19). Because of the aim of the C-RCT, participants in the intervention arm of the C-RCT were at increased risk for functional decline, based in the Identification of Seniors At Risk Primary Care screening questionnaire (ISAR PC) (20)). In the prospective cohort study, we included participants with and without an increased risk of functional decline based on the ISAR PC. The study was approved by the Medical Ethics Committee of the Academic Medical Centre, University of Amsterdam (protocol ID MEC10/182).

\section{Data collection and outcomes}

The self-reported questionnaire was conducted at baseline to all participants and included questions on multimorbidity, polypharmacy, activities of (instrumental) daily living (KATZ Activities of Daily Living ), cognition (Mini Mental State Examination), quality of life (EQ-6D), health care utilisation, psychological status (Rand 36 ) and falls (21). MCC was defined as having two or more chronic conditions (1) and based on a questionnaire to record MCC. This questionnaire consists of 17 pre-defined chronic conditions (e.g. diabetes, asthma, cancer) and is widely used in the Netherlands (22). Participants were asked whether they experienced the pre-defined morbidities in the last twelve months. After filling out the self-reported questionnaire, all participants were visited at home by a Community Care Registered Nurse (CCRN), who performed a comprehensive geriatric assessment (CGA) (19). In two out of twelve GPs in the intervention arm of the C-RCT and in all eight participating GP's in the prospective cohort study, the CGA started with five open questions on personal views on the ageing process and included 1) What does it mean for you to get older? 2) Do you worry about things? 3) What do you think the future will be like? 4) What, in your opinion, is needed for healthy ageing? and 5) What does quality of life mean to you? The CCRN summarized the answer on each question. The answer were recorded concisely by the CCRN.

\section{Statistical analyses}

Two researchers (RP, PV) independently analysed all answers to the five questions by means of an inductive content analysis (23). In the first step, the categories were derived from key words in the data in an inductive content analysis based on a random and representative sample of the answers of 200 participants (with and without MCC). Subsequently, each answer was classified into one of the defined categories. When persons addressed more than one category within one answer, the first two categories were noted. Only very few people addressed more than two categories. If the 
Table 1

Baseline Participant Characteristics

\begin{tabular}{|c|c|c|c|c|}
\hline Characteristics & $\begin{array}{l}\text { Persons with } \mathrm{MCC}^{*} \\
\mathrm{~N}=396(72 \%)\end{array}$ & $\begin{array}{l}\text { Persons without } \mathrm{MCC}^{*} \\
\qquad \mathrm{~N}=151(28 \%)\end{array}$ & P-value & $\begin{array}{c}\text { Total } \\
\mathrm{N}=547(100 \%)\end{array}$ \\
\hline \multicolumn{5}{|l|}{ Demographics } \\
\hline Age, in years (mean, SD) & $79.3(5.9)$ & $77.7(5.7)$ & 0.23 & $78.9(5.9)$ \\
\hline Female sex $(\mathrm{n}, \%)$ & $248(62.6)$ & $82(54.3)$ & 0.08 & $330(60.3)$ \\
\hline \multicolumn{5}{|l|}{ Level of education } \\
\hline Primary school or less $(\mathrm{n}, \%)$ & $85(21.5)$ & $27(17.9)$ & 0.65 & $112(20.5)$ \\
\hline Secondary education $(\mathrm{n}, \%)$ & $269(67.9)$ & $104(68.9)$ & & $373(68.2)$ \\
\hline College or university $(\mathrm{n}, \%)$ & $37(9.3)$ & $16(10.6)$ & & $53(9.7)$ \\
\hline \multicolumn{5}{|l|}{ Socioeconomic status } \\
\hline Low $(\%)$ & $267(67.4)$ & $121(80.1)$ & 0.01 & $388(70.9)$ \\
\hline Intermediate $(\%)$ & $97(24.5)$ & $26(17.2)$ & & $123(22.5)$ \\
\hline High $(\%)$ & $31(7.8)$ & $4(2.6)$ & & $35(6.4)$ \\
\hline Married / living together $(\mathrm{n}, \%)$ & $168(42.4)$ & $81(53.6)$ & 0.06 & $249(45.5)$ \\
\hline \multicolumn{5}{|l|}{ Living situation } \\
\hline Independent, alone (n, \%) & $213(53.8)$ & $69(45.7)$ & 0.08 & $282(51.6)$ \\
\hline Home for the elderly $(\mathrm{n}, \%)$ & $182(45.0)$ & $80(53.0)$ & & $262(47.9)$ \\
\hline \multicolumn{5}{|l|}{ Clinical characteristics } \\
\hline Polypharmacy a $(\geq 5)(n, \%)$ & $216(43.4)$ & $36(23.8)$ & $<0.001$ & $252(46.1)$ \\
\hline Modified Katz-ADL index b (mean, SD) & $2.4(2.3)$ & $0.8(1.3)$ & $<0.001$ & $1.9(2.2)$ \\
\hline ADL impairment (mean, SD) & $0.7(0.9)$ & $0.2(0.4)$ & $<0.001$ & $0.6(0.8)$ \\
\hline IADL impairment (7 items) (mean, SD) & $1.3(1.6)$ & $0.4(1.0)$ & $<0.001$ & $1.1(1.5)$ \\
\hline Cognitive functioning c (mean, SD) & $27.9(3.3)$ & $28.0(2.6)$ & 0.09 & $27.9(2,4)$ \\
\hline Health-related quality of life d (mean, SD) & $0.8(0.2)$ & $0.9(0.1)$ & $<0.001$ & $0.8(0.2)$ \\
\hline Psychological health status e (mean, SD) & $70.2(18.7)$ & $79.2(15.8)$ & 0.01 & $72.7(18.3)$ \\
\hline Quality of Life f, (mean, SD) & $7.5(1.0)$ & $7.8(0.9)$ & 0.03 & $7.5(1.0)$ \\
\hline Falls $(\geq 1)$ in past 12 months $g(n, \%)$ & $139(35.1)$ & $34(22.5)$ & 0.01 & $173(31.6)$ \\
\hline
\end{tabular}

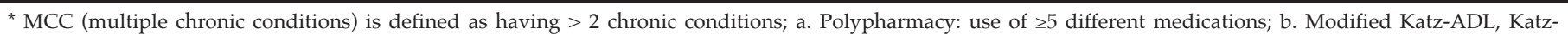

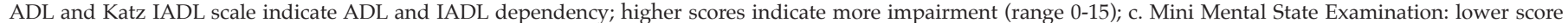

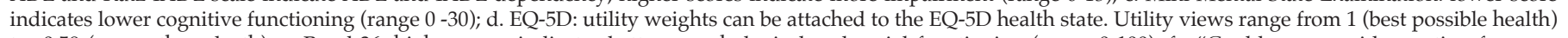

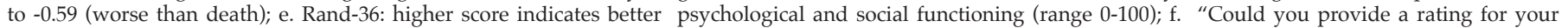
quality of life (0: very bad - 10: very good)?"; g. "Have you experienced one or more falls in the past 12 months?"

categories contained less than $5 \%$ of the total number of answers in both groups, they were included in the category 'other'. Descriptive statistics were used to characterize the participants with and without MCC. Due to the original qualitative nature of the data regarding the five questions, quantitative statistics have limited applicability. However, to compare the groups at baseline we used chi square tests and independent sample t-tests as appropriate. The same procedure was followed to compare the personal views on the ageing process in older persons with and without MCC. We used SPSS (version 21.0) for the statistical analyses.

\section{Results}

\section{Participants}

Data regarding the subject of this study were collected among 547 participants. A flowchart of the inclusion is shown in Figure 1. The characteristics of the 547 participants are presented in Table 1. In total, 396 participants $(72 \%)$ had MCC. There were no statistically significant differences in the demographic characteristics between persons with and without MCC. However, persons with MCC compared to those without MCC more often had polypharmacy $(43 \%$ vs $24 \%$; $\mathrm{p}<0.001)$, 
Table 2

Personal views on the ageing process

\begin{tabular}{|c|c|c|c|c|}
\hline \multirow[b]{3}{*}{ Emerging themes } & \multirow[b]{3}{*}{ Example } & $\begin{array}{l}\text { Persons } \\
\text { with } \text { MCC }^{*}\end{array}$ & \multirow{3}{*}{$\begin{array}{l}\text { Persons } \\
\text { without } \mathrm{MCC}^{*} \\
\mathrm{~N}^{* *}=171 \\
\%(\mathrm{n})\end{array}$} & \multirow{3}{*}{$\begin{array}{l}\text { Total } \\
\mathrm{N}^{* *}=648 \\
\%(\mathrm{n})\end{array}$} \\
\hline & & $\mathrm{N}^{* *}=477$ & & \\
\hline & & $\%(\mathrm{n})$ & & \\
\hline \multicolumn{5}{|l|}{ Question: What does it mean for you to get older? } \\
\hline $\begin{array}{l}\text { Having to address decline and } \\
\text { limitations }\end{array}$ & "Getting older is not so bad; it's the limitations that are a nuisance" & $19.3(92)$ & $12.9(22)$ & $17.6(114)$ \\
\hline A positive experience & $\begin{array}{l}\text { "After a studying and working phase, I'm now in the phase of } \\
\text { 'enjoying life" }\end{array}$ & $14.9(71)$ & $12.2(21)$ & $14.2(92)$ \\
\hline A negative experience & “I don't like it; I'm only going ‘down'” & $14.9(71)$ & $12.9(22)$ & $14.4(93)$ \\
\hline Acceptance & "Yes, one gets older; little can be changed about that" & $14.1(67)$ & $19.3(33)$ & $15.4(100)$ \\
\hline No difficulties & "I've experienced no problems" & $8.8(42)$ & $11.7(20)$ & $9.6(62)$ \\
\hline It has no specific meaning & "It just happens; it doesn't bother me" & $7.8(37)$ & $8.2(14)$ & $7.8(51)$ \\
\hline Fine, if my condition remains as it is & $\begin{array}{l}\text { "I don't mind getting older, as long as I don't experience physical } \\
\text { discomfort" }\end{array}$ & $7.3(35)$ & $11.7(20)$ & $8.5(55)$ \\
\hline Other & & $13.0(62)$ & $11.1(19)$ & $12.5(81)$ \\
\hline \multicolumn{5}{|l|}{ Question: Do you worry about things? } \\
\hline No Worries & "No" & $51.9(237)$ & $63.7(109)$ & $55.1(346)$ \\
\hline Worries & "Yes" (no further explanation) & $21.9(119)$ & $19.3(33)$ & $24.2(152)$ \\
\hline Worries about deterioration & "Yes, I worry about having ailments that add up" & $8.4(38)$ & $5.9(10)$ & $7.6(48)$ \\
\hline Worries about family & $\begin{array}{l}\text { "Yes, I worry about my husband and that I won't be able to provide } \\
\text { care for him anymore" }\end{array}$ & $6.1(28)$ & $5.9(10)$ & $6.1(38)$ \\
\hline Other & & $7.7(35)$ & $5.3(9)$ & $7.0(44)$ \\
\hline \multicolumn{5}{|l|}{ Question: What do you think the future will be like? } \\
\hline $\begin{array}{l}\text { Hoping or expecting the situation to remains } \\
\text { as is }\end{array}$ & "If it continues the way it is going now, great" & $18.1(75)$ & $20.3(31)$ & $19.0(106)$ \\
\hline Having an overall negative vision of the future & "It will probably all get worse slowly; I feel pessimistic about it" & $17.9(74)$ & $16.3(25)$ & $17.5(99)$ \\
\hline Don't know & "I cannot foresee the future" & $16.2(67)$ & $19.0(29)$ & $16.9(96)$ \\
\hline $\begin{array}{l}\text { It cannot be influenced, just have to wait and } \\
\text { see }\end{array}$ & "The future will present itself" & $13.5(56)$ & $14.4(22)$ & $13.8(78)$ \\
\hline Dreading more limitations & "I think it will get worse because of the discomforts". & $10.6(44)$ & $3.3(5)$ & $8.6(49)$ \\
\hline Having an overall positive vision of the future & "If things continue like this, I'll make it to $95^{\prime \prime}$. & $7.7(32)$ & $13.1(20)$ & $9.2(52)$ \\
\hline Maybe a change in living conditions & $\begin{array}{l}\text { "I live in a house, but I want to move to a flat because there will be } \\
\text { no stairs". }\end{array}$ & $6.0(25)$ & $5.9(9)$ & $6.0(34)$ \\
\hline Other & & $9.9(41)$ & $7.9(12)$ & $9.4(53)$ \\
\hline \multicolumn{5}{|c|}{ Question: What, in your opinion, is needed for healthy ageing? } \\
\hline $\begin{array}{l}\text { A healthy lifestyle, balance between activity } \\
\text { and rest }\end{array}$ & "Go to bed on time, eat well and exercise" & $51.5(225)$ & $54.4(98)$ & $52.4(323)$ \\
\hline Keeping busy and interested & "To do a lot, have hobbies, leave the house a lot" & $12.4(54)$ & $15.0(27)$ & $13.1(81)$ \\
\hline Social contacts, family & "To keep being among other people and to not grow lonely" & $7.1(31)$ & $8.3(15)$ & $7.5(46)$ \\
\hline Having a positive attitude toward life & "Being cheerful is very important to me to be happy" & & & \\
\hline Other & & $22.9(100)$ & $11.7(21)$ & $19.6(121)$ \\
\hline \multicolumn{5}{|l|}{ Question: What does quality of life mean to you? } \\
\hline Being able to do what you want to do & "To have a normal life, to do what you are used to doing" & $16.7(74)$ & $20.0(35)$ & $17.6(109)$ \\
\hline Health (both physical and mental) & "That I can wake up healthy every day" & $16.7(74)$ & $21.7(38)$ & $18.1(112)$ \\
\hline I am positive about my quality of life & “I still enjoy every day of life!” & $16.4(73)$ & $14.3(25)$ & $15.8(98)$ \\
\hline Social contacts, family and friends around you & "As long as I can socialize, for example with my family" & $15.8(70)$ & $10.3(18)$ & $14.2(88)$ \\
\hline That you are able to enjoy things & "To live pleasurably, to have a broad interest in all things" & $9.9(44)$ & $14.3(25)$ & $11.2(69)$ \\
\hline Staying independent & "To stay independent as long as possible" & $8.3(37)$ & $8.6(15)$ & $8.4(52)$ \\
\hline Other & & $16.2(72)$ & $10.9(19)$ & $14.7(91)$ \\
\hline
\end{tabular}

${ }^{*} \mathrm{MCC}$ is defined as having $>2$ chronic conditions; ${ }^{* *} \mathrm{n}=$ As persons could address multiple themes in one question, $\mathrm{N}$ represents the number of answers and not the number of persons. 
experienced more difficulties with (instrumental) activities of daily living (mean number of impairments 2.4 vs $0.8 ; \mathrm{p}<0.001)$ and a lower health-related quality of life (20\% vs $10 \%$; $\mathrm{p}<0.001)$. Furthermore, their psychological health status was lower (19\% vs $16 \%$; $\mathrm{p}=0.01)$, and they reported to have had more falls ( $35 \%$ vs $23 \% \mathrm{p}=0.01)$.

\section{Personal views on the ageing process}

Table 2 shows the categories and themes that the participants addressed answering the five questions with regard to personal views on the ageing process. We described the emerging themes for each question and provided an example for each theme.

\section{What does it mean for you to get older?}

"Getting older is not so bad; it's the limitations that become a nuisance"

In answering the question 'What does it mean for you to get older?', the respondents addressed the following themes: 'having to manage decline and limitations' $(17.6 \%)$, 'a positive experience' $(14.2 \%)$, 'a negative experience' (14.4\%), 'acceptance' (15.4\%), 'no difficulties' $(9.6 \%)$, 'no specific meaning' $(7.8 \%)$ and 'fine, if my condition remains as it is' $(8.5 \%)$.

\section{Do you worry about things?}

"I worry about my husband and that I can't provide care for him anymore"

In response to the question 'Do you worry about things?', $24.2 \%$ of the persons expressed worries. Of those who expressed worries, the concerns were focused on 'deterioration' $(37.0 \%)$ and 'family' $(29.0 \%)$. The other respondents $(34.0 \%)$ did not specify the nature of their worries.

\section{What do you think the future will be like?}

"If it continues the way it is going now, great"

Persons addressed the following themes for the question 'What do you think the future will be like?': 'hoping or expecting the situation to remain as is' (19.0\%), 'having an overall negative view on the future' (17.5\%) and 'don't know' (16.9\%). Other themes that were addressed by the respondents were as follows: 'it cannot be influenced, just have to wait and see' (13.8\%), 'fearing more limitations' (8.6\%), 'having an overall positive view on the future' $(9.2 \%)$ and 'maybe a change in living conditions' $(6.0 \%)$.
Figure 1

Flowchart of the participants

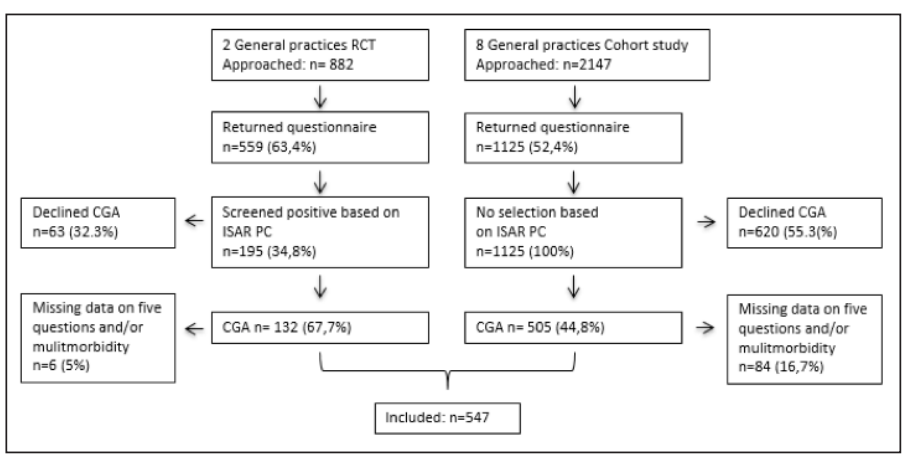

What, in your opinion, is needed for healthy ageing?

"Go to bed on time, eat well and exercise"

In answering the question 'What, in your opinion, is needed for healthy ageing?', the majority of the respondents answered 'a healthy lifestyle, balance between activity and rest' (52.4\%). A smaller proportion of persons addressed the following themes: 'keeping busy and interested' (13.1\%), maintaining social contacts, family' $(7.5 \%)$ and 'having a positive attitude to life' $(7.5 \%)$.

\section{What does quality of life mean to you?}

"That I can wake up healthy every day"

In response to the question 'What does quality of life mean to you?', the persons addressed the following themes: 'health (both physical and mental)' (18.1\%), 'being able to do what you want to do' (17.6\%), 'having social contacts, family and friends around you' (14.2\%), 'that you are able to enjoy things' (11.2\%) and 'remaining independent' $(8.4 \%)$. Some persons did not define quality of life but expressed their feeling about it: 'I am positive about my quality of life' $(15.8 \%)$.

\section{Differences between older persons with and without MCC}

For four of the 28 sub-themes statistically significant differences were found between participants with MCC compared to participants without MCC. With regard to the question 'What does it mean for you to get older?' persons with MCC more often mentioned 'having to address deterioration and limitations' compared to persons without MCC (19.4\% vs $12.9 \%$, $\mathrm{p}=0.03)$. Persons with MCC less frequently reported for the question 'Do you worry about things?' that they had no worries compared to those without MCC $(51.9 \%$ vs $63.7 \%$, $\mathrm{p}=0.01$ ). With regard to the question 'What do you think the future will be like?' persons with MCC expressed 'dreading more limitations' more often compared to 
persons without MCC ( $10.6 \%$ vs $3.3 \%, p=0.02)$. Finally, regarding the question 'What, in your opinion, is needed for healthy ageing?' persons with MCC said 'having a positive attitude to life' less often compared to persons without MCC (6.2\% vs $10.6 \%$, p=0.03).

\section{Discussion}

In this study, we explored which personal views older persons have regarding the ageing process and if there were differences in personal views between older persons with and without MCC. The personal views that were communicated most often were the association of ageing with (further) deterioration, acceptance of ageing and worries about limitations and family. Healthy lifestyles, staying active, keeping social contacts and a positive attitude were considered prerequisites to healthy ageing. The ability to do what one wants to do, good health and social contacts contributes to quality of life. Persons with MCC experienced more impairments in activities of daily living and had a lower health-related quality of life and a lower psychological health status compared to those without MCC. Older persons with and without MCC addressed many of the same topics regarding the ageing process but an important difference was that persons with MCC had more worries, had a more negative view on the future and especially feared further physical deteriorations and limitations.

The 28 sub-themes we identified regarding the personal views on the ageing process are consistent with studies that focus on successful ageing (24-26). In studies that focus on the factors that define successful ageing (24), participants highlighted that being able to do what you want to do, good health and social contacts are prerequisites for healthy ageing and quality of life and not solely the absence of physical limitations. Moreover, many participants in studies focussing on successful ageing mentioned the importance of a positive attitude to cope with the decline in health many of the participants experienced. This is a key feature of the resilience literature that is a further development of the successful ageing movement $(25,26)$. Resilience focuses on a person's lifelong search to find a balance between limitations and opportunities, also encompassing a social view on health. Many factors addressed by older persons in our study focused on this social view on health, such as maintaining social contacts and being able to do what they wanted to do.

In our study participants identified the preservation of physical function as an important factor contributing to quality of life. The importance of preservation of physical function has also been found in previous studies on outcomes that are important to older persons with MCC. For example, the study of Fried et al (28) emphasises the importance of functional outcomes for patients when they consider a treatment. Although we did not find many differences between older persons with and without
MCC, those with MCC had more worries and specifically about further deteriorations. At the start of the study they already had more impairment in ADLs. Therefore, this group is at higher risk to develop new disabilities because of their chronic conditions and more frequent hospitalizations (1). It indicates that for older persons with MCC the prevention of functional decline becomes more important.

We expected to find more differences between persons with and without MCC but the differences in personal views were limited. A first explanation might be that the five questions were not asked in the context of a treatment decision. Maybe personal views change when facing an actual treatment decision and differences between patients with and without MCC might become visible. Another explanation could be that the nature and duration of the existing comorbidities influence personal views. According to Gijsen et al (1) the consequences of specific disease combinations vary and depend on many factors. It is possible that specific combinations of coexisting morbidities do influence a person's view on the ageing process, but we were not able to explore this in our study.

The strength of this study is that we were able to assess personal views in more than 500 older participants, and were able to confirm that many older persons have the same personal views on the ageing process and what is needed for healthy ageing and quality of life. However, this study has some limitations. First the inclusion of the five questions used to gain insight into aspects that matter to older persons was recommended by CCRN and has no theoretical basis. Furthermore, the answers were written interpretations recorded concisely by the CCRN, which may have caused some bias. Future in-depth interviews on the answers could provide more insight into the underlying views of persons and the influence of these views on health decisions.

In conclusion, the results of this study show that older persons with and without MCC perceive a broad range of personal views as important in their stage of life. Those views can influence the health-related decisions that need to be made regarding diagnostics, treatment and care. For older persons with MCC fear of deterioration is a relevant topic to discuss because of the impact on quality of life: interaction with family members, good physical and mental health and being able to do what you want to do. When eliciting a patients views in the context of a treatment decision, MCC must be taken into account because of their influence on functional outcomes and the impact of that on quality of life. The results of this study may help raise awareness amongst health care professionals that questioning and understanding individuals' views can contribute to making health decisions that support an individual's personal goals and expectations. 


\section{Keypoints}

- Older persons with multiple chronic conditions face many health decisions.

- Multiple chronic conditions influence older person's goals and expectations for diagnostic procedures, treatments and care.

- Eliciting personal views facilitates the discussion about personal goals when facing health decisions, as a first step in the shared decision making process.

- In general, personal views address acceptance of ageing, fear of deterioration and worries about limitations and family.

- Having multiple chronic conditions does not seem to change views on ageing.

Acknowledgements: We are grateful to Paul de Vreede for his guidance on the statistical analysis.

Funding: This work was supported by ZonMw [grant number 520002002]. The sponsors had no role in the design and conduct of the study; in the collection, analysis, and interpretation of data; in the preparation of the manuscript; or in the review or approval of the manuscript.

Author disclosures: all authors: no conflicts of interest.

Ethical standard: The authors declare that there are no competing interests regarding the publication of this manuscript.

\section{References}

1. Gijsen R, Hoeymans N, Schellevis FG, Ruwaard D, Satariano WA, van den Bos GA. Causes and consequences of comorbidity: a review. Journal of clinical epidemiology. 2001;54(7):661-74.

2. Guiding principles for the care of older adults with multimorbidity: an approach for clinicians: American Geriatrics Society Expert Panel on the Care of Older Adults with Multimorbidity. Journal of the American Geriatrics Society. 2012;60(10):E1-e25.

3. van Weel C, Schellevis FG. Comorbidity and guidelines: conflicting interests. Lancet. 2006;367(9510):550-1.

4. Tinetti ME, McAvay GJ, Chang SS, Newman AB, Fitzpatrick AL, Fried TR, et al. Contribution of multiple chronic conditions to universal health outcomes. Journal of the American Geriatrics Society. 2011;59(9):1686-91.

5. Parker MG, Thorslund M. Health trends in the elderly population: getting better and getting worse. The Gerontologist. 2007;47(2):150-8.

6. Elwyn G, Lloyd A, May C, van der Weijden T, Stiggelbout A, Edwards A, et al. Collaborative deliberation: a model for patient care. Patient education and counseling. 2014;97(2):158-64.

7. Stiggelbout AM, Van der Weijden T, De Wit MP, Frosch D, Legare F, Montori $\mathrm{VM}$, et al. Shared decision making: really putting patients at the centre of healthcare. BMJ (Clinical research ed). 2012;344:e256.

8. Godolphin W. Shared decision-making. Healthc Q. 2009;12 Spec No Patient:e186-90.

9. McMahan RD, Knight SJ, Fried TR, Sudore RL. Advance care planning beyond advance directives: perspectives from patients and surrogates. J Pain
Symptom Manage. 2013;46(3):355-65

10. Fried TR, McGraw S, Agostini JV, Tinetti ME. Views of older persons with multiple morbidities on competing outcomes and clinical decision-making. Journal of the American Geriatrics Society. 2008;56(10):1839-44.

11. Tsevat J, Dawson NV, Wu AW, Lynn J, Soukup JR, Cook EF, et al. Health values of hospitalized patients 80 years or older. HELP Investigators. Hospitalized Elderly Longitudinal Project. Jama. 1998;279(5):371-5.

12. Elwyn G, Frosch D, Thomson R, Joseph-Williams N, Lloyd A, Kinnersley P, et al. Shared decision making: a model for clinical practice. Journal of general internal medicine. 2012;27(10):1361-7.

13. van de Pol MH, Fluit CR, Lagro J, Slaats YH, Olde Rikkert MG, LagroJanssen AL. Expert and patient consensus on a dynamic model for shared decision-making in frail older patients. Patient education and counseling. 2016;99(6):1069-77.

14. Fried TR, Tinetti M, Agostini J, Iannone L, Towle V. Health outcome prioritization to elicit preferences of older persons with multiple health conditions. Patient education and counseling. 2011;83(2):278-82.

15. Joseph-Williams N, Edwards A, Elwyn G. Power imbalance prevents shared decision making. BMJ (Clinical research ed). 2014;348:g3178.

16. Fried TR, Tinetti ME, Iannone L. Primary care clinicians' experiences with treatment decision making for older persons with multiple conditions. Archives of internal medicine. 2011;171(1):75-80.

17. Belcher VN, Fried TR, Agostini JV, Tinetti ME. Views of older adults on patient participation in medication-related decision making. Journal of general internal medicine. 2006;21(4):298-303.

18. Suijker JJ, van Rijn M, Buurman BM, Ter Riet G, Moll van Charante EP, de Rooij SE. Effects of Nurse-Led Multifactorial Care to Prevent Disability in Community-Living Older People: Cluster Randomized Trial. PLoS One. 2016;11(7):e0158714.

19. Suijker JJ, Buurman BM, ter Riet G, van Rijn M, de Haan RJ, de Rooij SE, et al. Comprehensive geriatric assessment, multifactorial interventions and nurseled care coordination to prevent functional decline in community-dwelling older persons: protocol of a cluster randomized trial. BMC health services research. 2012;12:85.

20. Suijker JJ, Buurman BM, van Rijn M, van Dalen MT, ter Riet G, van Geloven $\mathrm{N}$, et al. A simple validated questionnaire predicted functional decline in community-dwelling older persons: prospective cohort studies. Journal of clinical epidemiology. 2014;67(10):1121-30.

21. Lutomski JE, Baars MA, Schalk BW, Boter H, Buurman BM, den Elzen WP, et al. The development of the Older Persons and Informal Caregivers Survey Minimum DataSet (TOPICS-MDS): a large-scale data sharing initiative. PloS one. 2013;8(12):e81673.

22. CBS, GGD. Gezondheidsmonitor-2012. https:// wwwcbsnl/nl-nl/ maatwerk/2013/37/uitkomsten-gezondheidsmonitor-2012. 2013.

23. Elo S, Kyngas H. The qualitative content analysis process. Journal of advanced nursing. 2008;62(1):107-15.

24. Reichstadt J, Sengupta G, Depp CA, Palinkas LA, Jeste DV. Older adults' perspectives on successful aging: qualitative interviews. The American journal of geriatric psychiatry : official journal of the American Association for Geriatric Psychiatry. 2010;18(7):567-75

25. Cosco TD, Prina AM, Perales J, Stephan BC, Brayne C. Lay perspectives of successful ageing: a systematic review and meta-ethnography. BMJ open. 2013;3(6).

26. Martinson M, Berridge C. Successful aging and its discontents: a systematic review of the social gerontology literature. The Gerontologist. 2015;55(1):58 69.

27. Huber M, Knottnerus JA, Green L, van der Horst H, Jadad AR, Kromhout D, et al. How should we define health? BMJ (Clinical research ed) 2011;343:d4163.

28. Fried TR, Bradley EH, Towle VR, Allore H. Understanding the treatment preferences of seriously ill patients. N Engl J Med. 2002;346(14):1061-6. 